\title{
Bänziger H (2021) \\ Vampire moths. Behaviour, ecology and taxonomy of blood-sucking Calyptra.
}

\author{
Peter J. Schwendinger ${ }^{1}$, Bernard Landry ${ }^{1}$ \\ 1 Muséum d'histoire naturelle de Genève, Geneve, Switzerland \\ http://zoobank.org/002B936D-ECB7-427C-964F-2A1C01F4FEF0 \\ Corresponding author: Peter J. Schwendinger (peter.schwendinger@ville-ge.ch)
}

Academic editor: Thibault Lachat • Received 1 October 2021 • Accepted 11 November 2021 • Published 22 November 2021

$26 \times 19.3 \mathrm{~cm}, 232 \mathrm{pp}$. (including 2 short taxonomic appendices), hardbound, glossy paper, 263 colour photos (including close-ups), $1 \mathrm{~b} / \mathrm{w}$ photo, 114 $\mathrm{b} / \mathrm{w}$ drawings and diagrams, in English; ISBN 978-983-812-199-6, Natural History Publications (Borneo), Kota Kinabalu, Malaysia, 2021; price 50 US\$ (shipment not included), available from the author, e-mail: hans.banziger@cmu. ac.th, or $250 \mathrm{RM}$ (Malaysian ringgit; costs of shipment not included and presumably almost as much as the book price) from the publisher.

Lepidoptera not only visit flowers and feed on nectar many of us have also seen them sucking on less pleasant things like pus, urine and faeces - but it is not widely known that some of them are true blood suckers. Eight of the 17 currently recognized species (one of them containing two newly reinstated subspecies) of the genus Calyptra (Erebidae) in Asia are known to penetrate the skin of mammals - including humans - with a specialized proboscis and imbibe fresh blood. Hans Bänziger, a Swiss entomologist living in Thailand and a long-time member of the Swiss Entomological Society, has studied these enigmatic moths in their natural environment since 1967 and provides a summary of his findings and of the current state of knowledge in this newly published book. It is mostly based on the author's patient and meticulous observations during 545 nights in Papua New Guinea, West Malaysia, Thailand, Laos, Sri Lanka, India

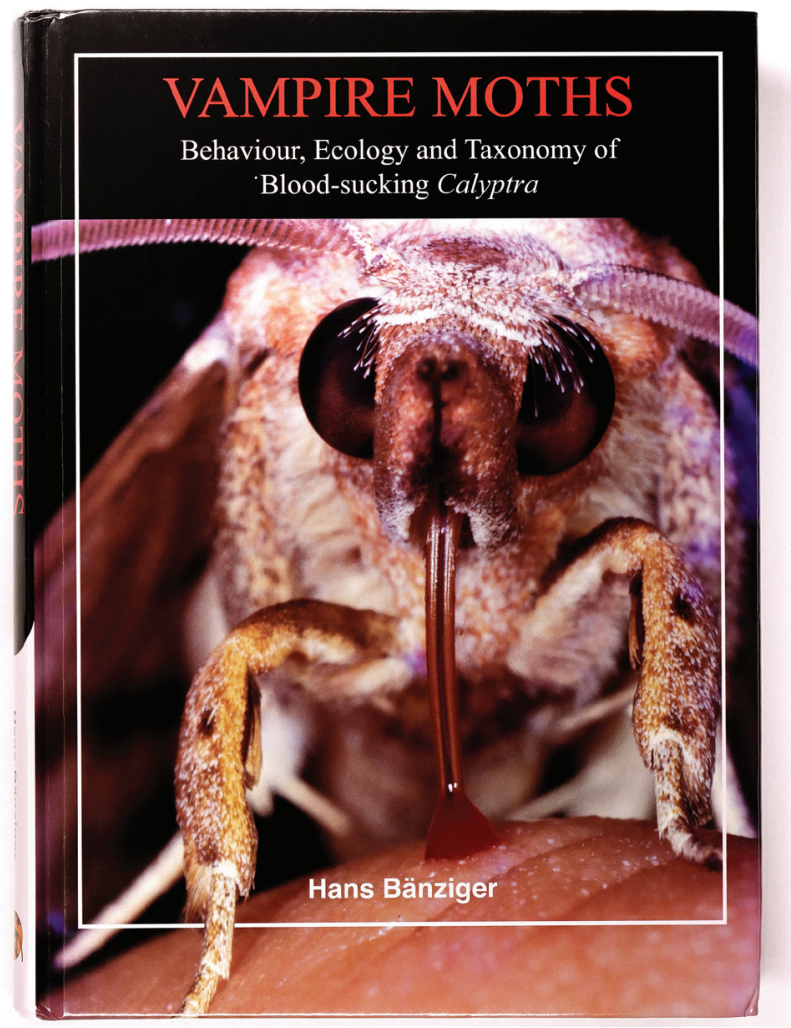

and Nepal. Hans Bänziger is a field entomologist par excellence, who spent countless hours, often under harsh conditions and alone at night, watching (more than catching) tear-sucking moths and fruit-piercing moths. During the day he concentrated on caterpillars, tear-drinking bees and pollinators of Paphiopedilum slipper orchids, Aristolochia, Rafflesia and Rhizanthes flowers.

In the first three chapters of this book the reader learns about how the author moved to that part of the world, about his diverse entomological activities and how he operated in the field, all nicely dressed with reminiscences 
and anecdotes. This is followed by a taxonomic treatment of the genus Calyptra and its close relatives, which includes an identification key to all species and subspecies, one lectotype designation, one generic synonymy, and the re-instatement of two subspecies. Four tables provide additional morphological characters and measurements. Furthermore, a detailed presentation of each taxon is given along with a list of the specimens examined, illustrations of the male genitalia, photos of habitus, larvae and their inconspicuous and often quite scarce food plants, as well as information on seasonality and habitat preferences.

The largest part of the book is an extensive and beautifully illustrated account of the author's observations (in the wild, in local zoos and enclosures for domestic animals) on how and on what these moths feed exactly. The human victim in all observed cases was the author himself. The specialized mechanism of skin-piercing by a modified proboscis is explained and illustrated, as is the evolution from fruit-piercing and sap-sucking to skin-piercing and blood-drinking. A surprising fact about this unusual (for moths) behaviour - about which we do not want to give away too much here - is that only Calyptra males feed on blood, and it is not for the most likely reason. Of note here is the convincingly presented argument that $C$. thalictri, the only species of the genus occurring in Europe, is not naturally haematophagous although it may draw mammal blood under constrained conditions.

We are not only impressed by the exotic nature of the book's subject and the presented wealth of difficult-to-obtain observations, but also by the high quality of the colour photos, almost all of which were taken with analogous cameras, in some instances over 30 years ago. The book ends with a topic that puts these so-called "vampire" moths in a very current spotlight: the potential transmission of pathogens (which is unlikely and still unproven).

This fascinating book, written in a rich vocabulary, is highly recommended for all lepidopterists, as well as entomologists, biologists, ecologists, veterinarians and medical doctors with an interest in exotic species and unusual animal behaviour. 